\title{
Pulmonary ventilation imaged by magnetic resonance: at the doorstep of clinical application
}

\author{
H.U. Kauczor*, X.J. Chen", E.J.R. van Beek", W.G. Schreiber*
}

Pulmonary ventilation imaged by magnetic resonance: at the doorstep of clinical application. H.U. Kauczor, X.J. Chen, E.J.R.van Beek, W.G. Schreiber. (C)ERS Journals Ltd 2001.

ABSTRACT: Over the past few years, magnetic resonance imaging (MRI) has emerged as an important instrument for functional ventilation imaging. The aim of this review is to summarize established clinical methods and emerging techniques for research and clinical arenas.

Before the advent of MRI, chest radiography and computed tomography (CT) dominated morphological lung imaging, while functional ventilation imaging was accomplished with scintigraphy. Initially, MRI was not used for morphological lung imaging often, due to technical and physical limitations. However, recent developments have considerably improved anatomical MRI, as well as advanced new techniques in functional ventilation imaging, such as inhaled contrast aerosols, oxygen, hyperpolarized noble gases (Helium-3, Xenon-129), and fluorinated gases (sulphur-hexafluoride). Straightforward images demonstrating homogeneity of ventilation and determining ventilated lung volumes can be obtained. Furthermore, new image-derived functional parameters are measurable, such as airspace size, regional oxygen partial pressure, and analysis of ventilation distribution and ventilation/perfusion ratios.

There are several advantages to using MRI: lack of radiation, high spatial and temporal resolution and a broad range of functional information. The MRI technique applied in patients with chronic obstructive pulmonary disease, emphysema, cystic fibrosis, asthma, and bronchiolitis obliterans, may yield a higher sensitivity in the detection of ventilation defects than ventilation scintigraphy, CT or standard pulmonary function tests.

The next step will be to define the threshold between physiological variation and pathological defects. Using complementary strategies, radiologists will have the tools to characterize the impairment of lung function and to improve specificity.

Eur Respir J 2001; 17: 1008-1023.
*Dept of Radiology, Johannes Gutenberg-Universitaet Mainz, Mainz, Germany, "Dept of Medical Biophysics, Sunnybrook and Women's College Health Sciences Centre, Toronto, Ontario, Canada and Section of Academic Radiology, Royal Hallamshire Hospital, Sheffield, UK.

Correspondence: H-U. Kauczor, Klinik und Poliklinik für Radiologie, Universitaet Mainz, Langenbeckstraße 1, DE55131 Mainz, Germany.

Fax: 466131176633

Keywords: Functional lung imaging hyperpolarization

inert noble gases

nonproton-magnetic resource imaging ventilation

Received: April 172001

Accepted after revision April 182001
Radiological imaging techniques have evolved from simple morphological assessment of the lung parenchyma to regional analysis of lung function by the introduction of well-defined strategies and technical refinements. Regional analysis will allow differentiation of normal physiological reactions and variants from early pathological changes associated with functional compromise. Radiological techniques are capable of providing new parameters, different from conventional pulmonary function tests (PFTs), which will allow for new insights in pulmonary physiology and pathophysiology. It will challenge the interdisciplinary collaboration between radiologists, pulmonologists, physiologists and physicists to assess and validate usefulness and impact of these new parameters. Challenges for radiological studies of pulmonary ventilation using magnetic resonance imaging (MRI) will comprise analysis of: 1) global lung function, such as measurement of static inspiratory and expiratory lung volumes; 2) regional lung function, such as ventilation per unit volume on a lobar segmental or subsegmental basis; 3) distribution of ventilation, such as comparative studies in inspiration and expiration, at equilibrium and wash-in/wash-out analysis, 4) different pulmonary functional units in relation to compartmentalization (e.g. determination of pulmonary time constants); 5) respiratory mechanics (i.e. diaphragmatic and chest wall motion, compliance, and resistance);

Previous articles in this series: No. 1: Ghaye B, Dondelinger RF. Imaging guided thoracic interventions. Eur Respir J 2001 ; 17 : 507-528. No. 2: Vansteenkiste JF, Stroobants SG. The role of positron emission tomography with ${ }^{18}$ F-fluoro-2-deoxy-D-glucose in respiratory oncology. Eur Respir J 2001; 17: $802-820$. 
and 6) oxygenation capacity (i.e. local ventilation/ perfusion ratio $\left(V^{\prime} / Q^{\prime}\right.$ ratio) and local oxygen partial pressure).

Ventilation is only one factor contributing to gas exchange, the predominant function of the lung. Pulmonary $Q^{\prime}$ and local $V^{\prime} / Q^{\prime}$ ratio are also of crucial importance. For the investigation of gas exchange, mainly oxygen uptake, imaging of ventilation has to be complemented by perfusion imaging with visualization of the pulmonary arteries (magnetic resonance angiography (MRA)) as well as quantitative determination of regional perfusion. The imaging of the ventilation process is thus essential in the assessment of the balance between perfusion and ventilation as a function for gas exchange. The pathological process can be related to ventilation, as is the case in chronic obstructive pulmonary disease (COPD) and asthma, or may be primarily a $Q^{\prime}$ disorder, such as chronic pulmonary hypertension (both thromboembolic and nonthromboembolic).

MRI-based strategies have the advantage of high spatial and temporal resolution as well as the potential for new approaches to pulmonary function without using ionizing radiation. In this review, nuclear medicine and computed tomography (CT) will be briefly reviewed and compared with newly developed MRI techniques.

\section{Nuclear medicine}

Until recently, nuclear medicine techniques were regarded as the imaging "gold standard" and widely used to visualize pulmonary ventilation. The two major uses of these techniques are: 1) complementing perfusion scintigraphy for the diagnosis of acute pulmonary embolism by a mismatch between perfusion defect and unchanged ventilation $[1,2]$; and 2) estimating the functional capabilities of the pulmonary parenchyma prior to lung resections in patients with COPD [3]. However, for the estimation of postoperative lung function (forced expiratory volume in one second (FEV1)) from a preoperative examination, perfusion scintigraphy is more reliable and accurate than ventilation scintigraphy [4]. Scintigraphy of ventilation can be carried out by using radioactive gases, such as Xenon-133 $\left({ }^{133} \mathrm{Xe}\right)$, Xenon-127 $\left({ }^{127} \mathrm{Xe}\right)$, Krypton-81m $\left({ }^{81 \mathrm{~m}} \mathrm{Kr}\right)$, or by using radioactive aerosols, such Technetium-99m ( $\left.{ }^{99 \mathrm{~m}} \mathrm{Tc}\right)$-diethylenetriaminepentaacetic acid (DTPA) and $99 \mathrm{~m}$ Tc-Technegas with carbon particles as carriers ("ultra-fine aerosol"). The gaseous compounds have the advantage of greater ease of distribution into the smaller airways, whereas the aerosols are more prone to central deposition, especially in COPD. For a more detailed review, the reader is referred to more specific texts $[5,6]$. Main drawbacks are the limitations in spatial and temporal resolution. Improved anatomical detail is offered by cross-sectional images (single photon emission computed tomography (SPECT)) with slice thickness of $15 \mathrm{~mm}$, and it has been shown to correlate well with lung function parameters in patients with emphysema [7, 8]. Highly sophisticated nuclear medicine techniques for ventilation imaging make use of positron emission tomography (PET) with short half-live $(17 \mathrm{~s}$ to $2 \mathrm{~h}$ ) isotopes (Nitrogen-13 $\left({ }^{13} \mathrm{~N}\right)$, Oxygen-15 $\left({ }^{15} \mathrm{O}\right)$, Neon-19 ( $\left.{ }^{19} \mathrm{Ne}\right)$, Carbon-11 $\left({ }^{11} \mathrm{C}\right)$ [9]. PET allows for an in-plane resolution of $\sim 10 \mathrm{~mm}$ and a temporal resolution near $30 \mathrm{~s}$. The potential for functional imaging of pulmonary ventilation seems to be highly diversified. The potential for broad clinical use, however, appears limited, since the technical requirements are very demanding $[10,11]$.

\section{Computed tomography}

CT is the imaging modality of choice for the morphological assessment of the pulmonary parenchyma with high spatial resolution (slice thickness down to $1 \mathrm{~mm}$ ). In addition, dedicated strategies can be used to estimate lung function [12]. Hypoventilated lung areas caused by expiratory obstruction are demonstrated by paired scans during an inspiratory and an expiratory breath-hold [13]. By using dynamic multirotation CT (spiral CT without table movement), however, a calculated temporal resolution of $100 \mathrm{~ms}$ can be achieved in a single slice [7, 14]. A dynamic study of the whole lung is not possible, even though new technical developments (multislice spiral CT) will enable coverage of the whole lung within approximately $5 \mathrm{~s}$. Postprocessing algorithms have been developed to derive functional information from CT datasets, such as density and area measurements, emphysema index, volumetry of ventilated airspaces, and diaphragmatic dimensions [15-18]. Attempts at direct visualization of ventilation using CT have been made, but were not introduced into clinical practice due to the difficulties encountered. One such attempt was having the subject inhale a xenon-oxygen mixture $(30-75 \% \mathrm{Xe})$ until equilibrium was reached. Due to its weight, $\mathrm{Xe}$ induced an increase in density of 40-100 Hounsfield units (HU) within the ventilated lung areas. This increase in lung density is quite small and required additional postprocessing [19]. An alternative approach is the use of an aerosolized contrast agent, which yields a density increase of 60-80 HU, again too small a difference to be clinically useful [20]. For both approaches only experimental preclinical data are available.

\section{General magnetic resonance imaging}

In the field of MRI, several new developments are being evaluated for functional studies of the lung and direct imaging of ventilation. Some of them are based on so-called conventional MRI, which makes use of the protons found in water in the body (H-1 MRI). Breathhold acquisitions allow for detection of intrapulmonary masses, interstitial disease and calculation of lung volumes. Rapid image acquisitions are used for dynamic assessment of respiratory mechanics. Extracellular contrast agents administered intravenously, mainly chelates of the rare-earth metal Gadolinium (Gd), are widely used in H-1 MRI. They are helpful for improved visualization of the pulmonary arteries (MRA) and for assessment of pulmonary perfusion 
[21-23]. Strictly intravascular contrast agents may be even better suited for the assessment of organ perfusion. To image ventilation directly, Gd-chelates have been applied as an aerosol. Since oxygen has paramagnetic properties, it can also be used as an inhaled contrast agent for direct imaging of pulmonary ventilation. Besides H-1 MRI, other nuclei can be used for MRI (nonproton-MRI). They include Helium-3 $\left({ }^{3} \mathrm{He}\right)$, Xenon-129 $\left({ }^{129} \mathrm{Xe}\right)$ and Fluorine-19 $\left({ }^{19} \mathrm{~F}\right) .{ }^{3} \mathrm{He}$ and ${ }^{129} \mathrm{Xe}$ are inert gases, and they can be applied easily by inhalation. ${ }^{19} \mathrm{~F}$ can be applied in gaseous form as sulphur-hexafluoride $\left(\mathrm{SF}_{6}\right)$ or as a liquid perfluorocarbon (perflubron) in partial or total liquid ventilation. These emerging techniques will provide direct visualization as well as quantitative and functional data about ventilation. In the following sections, the available techniques for acquisition and postprocessing are briefly described, and the potential clinical indications are reviewed.

\section{H-1 magnetic resonance imaging}

The low tissue density in the lung yields a very low magnetic resonance (MR) signal. Deleterious magnetic susceptibility effects, caused by the complex lung structure, further degrade the signal. Over the years, advances such as ventilation gating and improved pulse sequences have greatly improved quality in conventional MRI lung images (fig. 1). Some of these developments have been used for functional studies of ventilation and respiratory mechanics. Lung volumes can be easily segmented and calculated from MR images acquired at different respiratory levels such as at full inspiration (total lung capacity (TLC)) and full expiration (residual volume (RV)). In a clinical study $(\mathrm{n}=29)$, MRI systematically underestimated TLC and overestimated RV as compared with PFTs, yielding a good correlation $(\mathrm{r}=0.77)$ [24]. MRI-derived lung

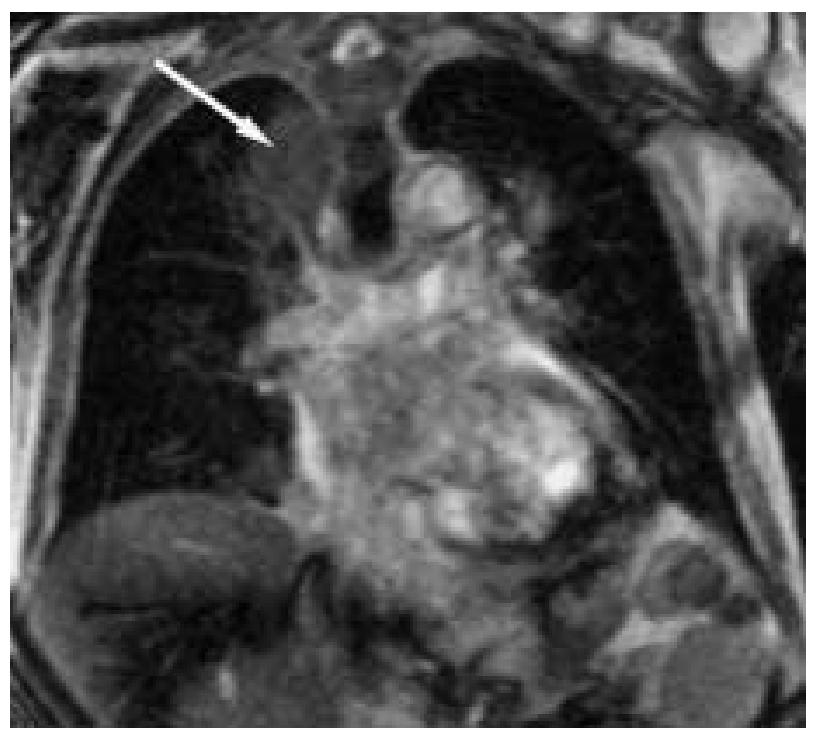

Fig. 1. - H-1 magnetic resonance image at $0.2 \mathrm{~T}$ (TrueFisp) of an 83-yr-old male showing pneumonia in both upper lobes (arrow). volumes were even better correlated with volumes calculated from spiral CT $(\mathrm{r}=0.87)$. This technique was also successfully used in patients before (pre) and after (post) lung volume reduction surgery [25]. The changes in thoracic dimensions were consistent with improved respiratory mechanics. In that study, dynamic MRI techniques have been applied to image diaphragmatic and chest wall motion during $2-3$ deep respiratory cycles with a temporal resolution of $1.3 \mathrm{~s} \cdot$ image $^{-1}$ and a spatial resolution of $\sim 2 \times 3 \times 10 \mathrm{~mm}$. Six volunteers and 28 patients with emphysema, nine of them pre and post lung volume reduction, were included in the study. For assessment of the synchronicity of diaphragmatic and chest wall motion, dynamic cine evaluation and fusion of inspiratory and expiratory images were performed. After normalization, maximum excursion and the ratio between diaphragmatic and chest wall motion were compared with PFT results $(\% \mathrm{FEV} 1, \%$ vital capacity (VC), \%TLC, \%RV). Volunteers showed synchronous movement of the diaphragm and chest wall without significant differences between right and left sides. Chest wall motion was significantly higher at the apices as compared with a more caudal level. Emphysema patients showed a markedly reduced and irregular motion of the diaphragm and chest wall, which frequently exhibited dissociated motion between apical and caudal levels. Maximum values were not significantly different among the volunteers, whereas minimum values in the emphysema group were significantly higher and the differences between inspiration and expiration were significantly reduced. The difference of the chest wall motion at the apical and the caudal level was no longer apparent in the emphysema patients. After lung volume reduction, a marked improvement of diaphragmatic and chest wall motion was noted. Overall, excellent correlation was found between MRI parameters and PFTs: maximum amplitude of diaphragmatic motion and $\% \mathrm{FEV} 1, \mathrm{r}=0.88$ and $\% \mathrm{VC}, \mathrm{r}=0.85$; maximum amplitude of chest wall motion and $\% \mathrm{FEV} 1, \mathrm{r}=0.91$. Thus, dynamic MRI allows for direct and quantitative assessment of impaired respiratory mechanics in emphysema patients making it a valuable examination for assessment of the effect of lung volume reduction surgery.

In a different study, 3D-reconstructions of the diaphragm and the chest wall were generated from MRI to describe the shape of the diaphragm and the rib cage in inspiration and expiration. This was done to quantify breathing volumes and to investigate the association between breathing volume and changes of the surface of the relevant parts of the diaphragm [26]. MRI of the chest was performed in five healthy volunteers at three different respiratory levels (TLC, functional residual capacity (FRC) and RV) in coronal and sagittal orientation. After manual segmentation and 3D-reconstruction, the diaphragm was divided in the central area (dome) and the peripheral apposition zone. Thus, the size of the diaphragm in all three orientations, as well as the surface area of the whole diaphragm $\left(1128 \mathrm{~cm}^{2}\right.$ at RV, $997 \mathrm{~cm}^{2}$ at FRC, and $584 \mathrm{~cm}^{2}$ at TLC), the dome and the apposition zone $\left(757 \mathrm{~cm}^{2}\right.$ at RV, $597 \mathrm{~cm}^{2}$ at FRC, and $0 \mathrm{~cm}^{2}$ at TLC), were measured. Comparing MR-based measurements of lung volumes with PFTs, MRI tended to 
overestimate RV and underestimate TLC. Between RV and TLC, the mean volume under the diaphragm decreased by $66 \%$, whereas the mean total volume of the rib cage increased by $23 \%$. The contribution of the diaphragm to the inspiratory capacity was $60 \%$.

\section{Contrast agents: intravenous administration}

The most widely employed technique used for MRA requires the administration of i.v. contrast agents, such as Gd-chelates. They all reduce the longitudinal relaxation time (T1-time) of blood, resulting in an increase in signal intensity, but are disadvantaged by removal from the circulation. Thus, imaging is performed best during the first pass of the contrast agent. This requires fast imaging, synchronization of the MRI acquisition with bolus arrival, and breathhold techniques. This technique delineates the pulmonary arterial vessels down to 5 th -6 th order [27]. It has been used in a clinical setting to study pulmonary embolism (both acute and chronic emboli) with reasonable success (fig. 2), although clinical management studies have not yet been performed [23, 28, 29]. Blood pool agents (ultra small super-paramagnetic iron oxide particles, coated Gd-complex compounds, albuminbinding agents) enable a more prolonged investigation time, greater spatial resolution or coverage and imaging of slow or complex blood flow [30].

Perfusion of lung parenchyma is one of the most important parameters in the determination of gas exchange complementing the assessment of lung ventilation. Strategies have been developed which make use of the first pass of a concentrated contrast bolus or blood pool agents [22, 31, 32]. Another technique uses specialized MR image sequences to

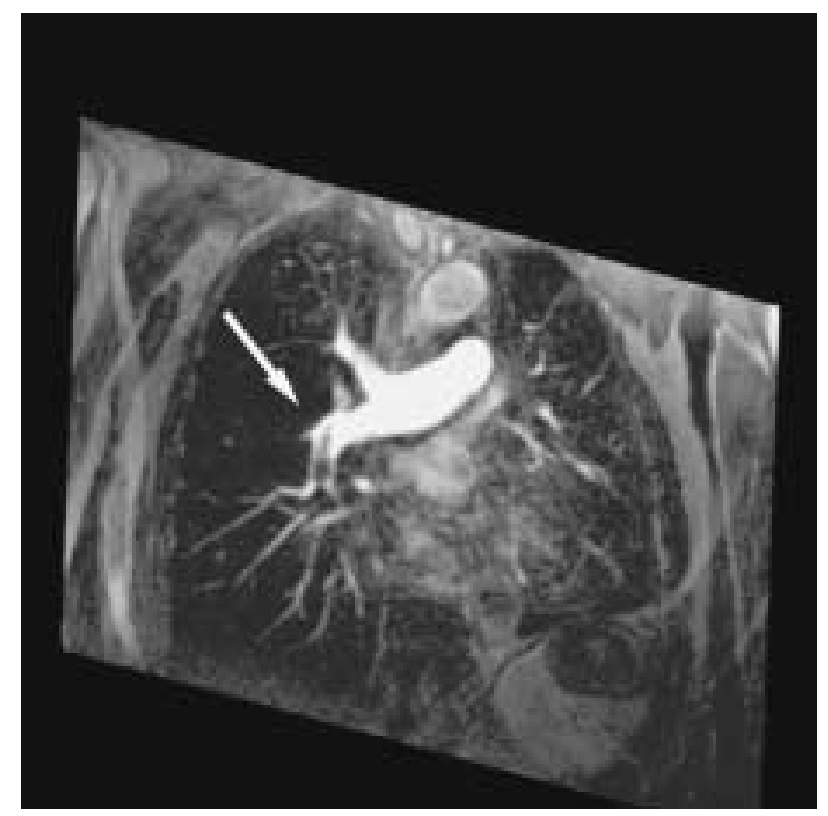

Fig. 2. - H-1 magnetic resonance angiography with intravenous administration of Gadolinium-diethylenetriaminepentaacetic acid in a 71-yr-old male showing acute pulmonary embolism in the right pulmonary artery (arrow). "tag" the flow of blood (arterial spin tagging) but is limited by insufficient spatial resolution, low signal-to noise, and long measurement times [33]. Most recently, an animal study showed the combined use of ventilation MRI (using hyperpolarized gases) and perfusion MRI, resulting in an over-lay technique showing $V^{\prime} / Q^{\prime}$ correlation [34]. The main advantages of MRI over scintigraphy in this respect are the greater spatial resolution, the incorporation of functional and anatomical data, visualization of the pulmonary arteries by MRA and the lack of ionizing radiation.

\section{Contrast agents: administration by inhalation}

In an attempt to directly visualize the pulmonary airways, several groups have tried to administer the widely used Gd-chelates by inhalation. In the beginning, the results were not convincing because very little contrast agent reached the small airways and airspaces. Even uses of different kinds of nebulizers, mixtures, dilutions and animal models were associated with a lot of difficulties. First studies in rats were performed in 1992, and an increase of $\sim 70 \%$ was observed [35]. The administration of aerosolized Gd-DTPA was successfully complemented by a perfusion study using an intravascular contrast agent for investigations of pulmonary embolism and bronchial obstruction in an animal model [35]. In a different study, commercially available Gd-DTPA was mixed with mannitol and a surface-active detergent. This modified contrast agent was aerosolized (particle size $0.5-5 \mu \mathrm{m}$ ) and administered to small animals. It gave high signal intensity from the alveolar space [36]. The preparation yielded a significantly higher increase in lung signal intensity than usually obtained from Gd-DTPA, since the osmotic effect of mannitol increased the density of the protons. At the same time the detergent reduced surface tension and lead to smaller droplets. In a recent study using a porcine model, more promising results have been obtained: Gd-DTPA was aerosolized and yielded a homogeneous distribution (fig. 3), and an average signal increase of $118 \%$ [37].

\section{Oxygen enhancement}

Oxygen can also be used as a contrast agent in $\mathrm{H}-1$ MRI, since its paramagnetic properties can affect the lung tissue and blood by direct contact. Dissolution of oxygen causes T1-time shortening in tissue and blood, resulting in a signal increase in affected areas as shown in a T1-time-weighted image. By taking the difference of two images, one with the subject breathing room air and the other when breathing $100 \%$ oxygen, ventilation can be imaged. The typical increase in signal intensity is in the order of $15 \%[38,39]$. The imaging sequence used is called inversion recovery [40], where variation of the inversion time can weight the image for $V^{\prime}$ or $Q^{\prime}$. Image quality and signal can be further improved by suppressing the signal from muscle and fat [41]. In combination with oxygen-enhancement, high signal visualization of the pulmonary parenchyma has been achieved as shown in figure 4 . Since the signal increase 


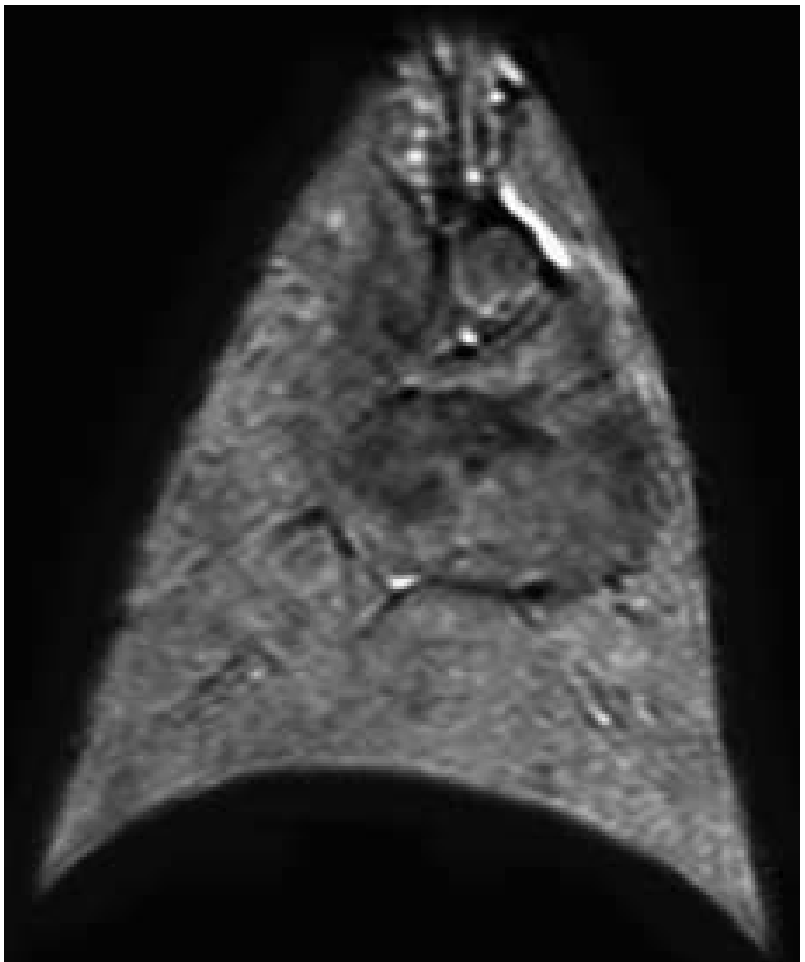

Fig. 3. - H-1 magnetic resonance image (coronal subtraction) following $20 \mathrm{~min}$ of mechanical aerosol delivery showing rather homogeneous Gadolinium-diethylenetriaminepentaacetic acid distribution. (Courtesy of P. Haage, Dept of Diagnostic Radiology, University of Technology, Aachen, Germany).

is mainly determined by oxygen in the capillaries and the lung veins, there was a higher increase in signal in the lung cortex than in the medulla [41].

In summary, ventilation imaging simply by changing

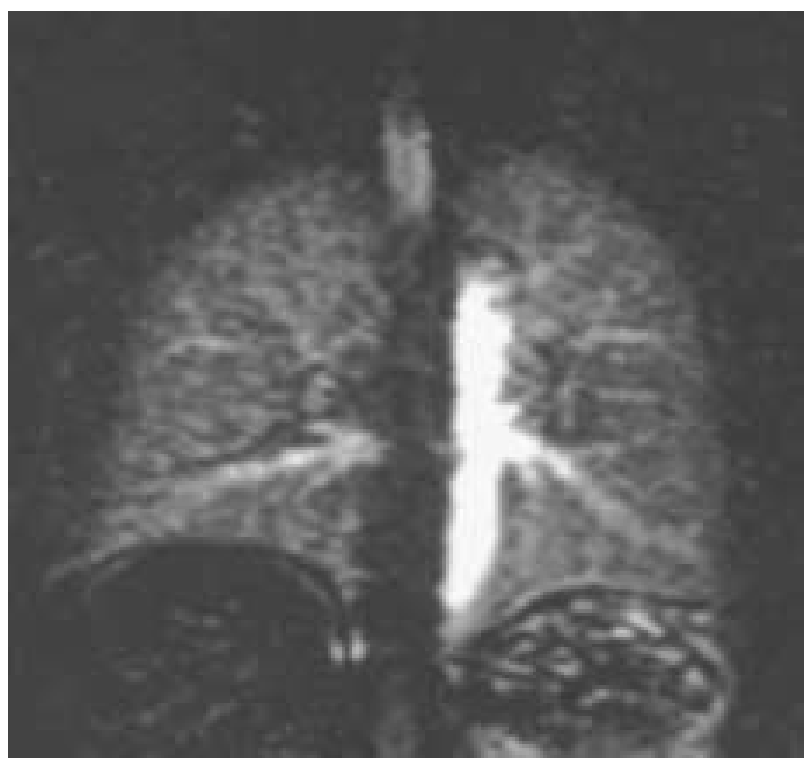

Fig. 4. - H-1 magnetic resonance image (multiple inversion recovery) with oxygen enhancement in a healthy volunteer showing homogeneous ventilation, enhancement of pulmonary veins and close to total background suppression. (Reproduced from [41] with permission). the inspiratory oxygen concentration is an attractive principle compared with sophisticated and complex techniques like hyperpolarized noble gases (see later). With appropriate postprocessing algorithms, this imaging technique can be easily implemented into a clinical routine (e.g. as a complementary step in the MRdiagnosis of acute pulmonary embolism [42]). Further applications include studies of regional oxygen uptake in obstructive and interstitial lung disease. It is unclear whether the individual contributions of regional changes of ventilation, diffusion (oxygen uptake) or perfusion to the overall gas exchange can be separated. One limitation of oxygen-enhanced imaging compared to using hyperpolarized gases, is the inability to perform dynamic imaging of ventilation, as images need to be taken at equilibrium of breath mixtures.

\section{Nonproton-magnetic resonance imaging}

\section{Hyperpolarized noble gases}

Utilizing hyperpolarized noble gases with MRI is a recent approach for ventilation imaging. In contrast to the proton-based techniques, a dedicated gas is used as a "contrast agent" to directly visualize the gas, rather than relying on indirect effect (e.g. oxygen on blood or tissue T1-time). Normally, the density of gases is too low to produce a detectable signal. This drawback is overcome by artificially increasing the amount of polarization per unit volume (hyper-polarization) using an optical pumping technique. Optical pumping (polarization) of inert noble gases, ${ }^{3} \mathrm{He}$ or ${ }^{129} \mathrm{Xe}$, was developed in the 1960s when physicists started experiments to elucidate the structure of the neutron [43, 44]. Two techniques for generating hyperpolarization have been established: 1) spin exchange: indirect transfer of angular momentum from a laser source to the nuclei of ${ }^{3} \mathrm{He}$ or ${ }^{129} \mathrm{Xe}$ using an alkali metal such as rubidium; and 2) metastability exchange: direct transfer of angular momentum from laser light to ${ }^{3} \mathrm{He}$ nuclei via a radio frequency discharge. A detailed review of advantages and disadvantages of either technique is beyond the scope of this article. The reader is referred to reviews and original articles in the literature $[45,46]$.

The two inert noble gases have different properties: 1) ${ }^{3} \mathrm{He}$ is a very rare isotope, which is a by-product from tritium (Hydrogen-3 $\left.\left({ }^{3} \mathrm{H}\right)\right)$ decay. It is particularly suited for ventilation studies since it has no known deleterious side-effects. Additionally, ${ }^{4} \mathrm{He}$, the stable counterpart of ${ }^{3} \mathrm{He}$ with similar physical properties, is widely used for decompression in deep-sea diving, special PFTs (measurement of FRC), and jet ventilation. 2) ${ }^{129} \mathrm{Xe}$ occurs more commonly, existing in quantities of $26 \%$ in naturally abundant Xe. Blood, fat, and tissue absorb Xe, making it promising for perfusion and gas exchange studies. An impediment to such studies is that in high concentrations and during prolonged exposure, $\mathrm{Xe}$ acts as an anaesthetic.

For the specific purposes of ventilation imaging, ${ }^{3} \mathrm{He}$ provides a number of advantages over ${ }^{129} \mathrm{Xe}$. The polarization is higher and the gyromagnetic ratio of ${ }^{3} \mathrm{He}$ is approximately three times higher than ${ }^{129} \mathrm{Xe}$, yielding a signal advantage of almost an order of 
magnitude [47]. Current techniques for ${ }^{3} \mathrm{He}$ yield polarization rates of $30-40 \%$ using spin-exchange [48, 49] and $35-50 \%$ using metastability exchange [50], whereas for ${ }^{129} \mathrm{Xe}$ they are only $5-7 \%[51-53]$. Finally, the lack of anaesthetic effects of ${ }^{3} \mathrm{He}$ has made clinical trial studies easier to expedite. The main disadvantage of ${ }^{3} \mathrm{He}$ is the limited availability compared to naturally abundant $\mathrm{Xe}$.

Most developments of hyperpolarized gas imaging have taken place on "standard" $1.5 \mathrm{~T}$ MR systems. Since the polarization is generated by optical pumping rather than by the magnetic field of the MR scanner, this technique is ideally suited for high-quality imaging in an open, low-field system [54]. Using such systems would lower the costs of the investigation, while the open concept would increase patient comfort, especially if dyspnoea is a problem. One of the drawbacks of low-field systems is that proton imaging is generally complimentary, both for anatomical detail as well as perfusion studies. Unfortunately, these studies become more difficult to perform in lowfield systems. Another interesting application is to perform MR in a physiological setting (i.e. with the patient in the upright position). Such a system would have significant implications for imaging of ventilation, as it would more closely match the physiological state.

\section{Gas density imaging in animals}

Initial efforts in imaging of hyperpolarized noble gases were focused on visualizing gas in the lungs during breath-hold. Such images are termed gas density because no special weightings or breathing techniques are used. One of the key differences between imaging hyperpolarized gas and conventional equilibrium protons is the lack of signal recovery with the gas. Because the gas is externally hyperpolarized, it is in a nonequilibrium state, so the application of radiofrequency pulses destroys the signal irreversibly. Thus, careful consideration of image sequences and parameters is required. The first demonstration of hyperpolarized ${ }^{129} \mathrm{Xe}$ imaging was in excised mouse lungs [55]. This was followed by ${ }^{3} \mathrm{He}$ lung imaging in guinea-pigs $e x$ vivo [47], and in vivo [45], as well as in vivo ${ }^{129} \mathrm{Xe}$ images in rats [56]. Using multiple breath-holds, high-resolution images of the airspaces can be acquired (fig. 5).

\section{Gas density imaging in humans}

As with the animal experiments, first studies in humans were gas density images of airways and alveolar airspaces in an inspiratory breath-hold, using either ${ }^{3} \mathrm{He}$ or ${ }^{129} \mathrm{Xe}[58-61]$. A typical image series requires a breath-hold period of $<10$ s to obtain $\sim 10$ coronal images covering the whole lung. Spatial resolution is significantly better than in nuclear medicine $(2.5 \times 2.5 \times 10 \mathrm{~mm}$ with $2-5 \mathrm{~mm}$ gap between slices). Assessment of the ${ }^{3} \mathrm{He}$ signal intensities revealed preferential ventilation of the posterior lung areas in supine position [50]. The same data can also be used to measure the volume of the ventilated airspaces, revealing a good correlation $(\mathrm{r}=0.88)$ with the results

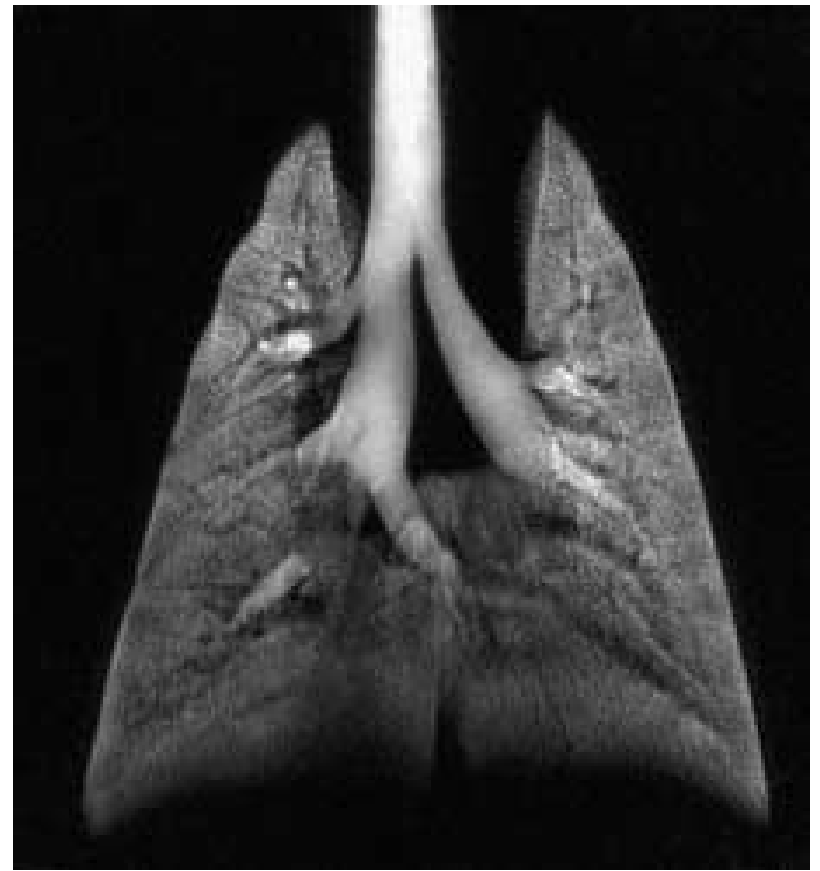

Fig. 5. - Helium-3 $\left({ }^{3} \mathrm{He}\right)$ magnetic resonance image after inhalation of hyperpolarized ${ }^{3} \mathrm{He}$ gas in an adult rat acquired during multiple breath-holds after full inspiration. (Reproduced from [57] with permission).

of PFTs [62]. Absolute lung volumes were estimated after introduction of additional correction factors.

Initially, investigators studying gas density imaging concluded that normal ventilation is represented by an almost complete and homogeneous distribution of the ${ }^{3} \mathrm{He}$ signal within the lung [63]. However, some small transient ventilation defects (order of $2 \mathrm{~cm}$ ) have been observed in healthy nonsmokers. Most of them were in the posterior lung fields and have been attributed to posture [64]. These defects are regarded as physiological, and illustrate the sensitivity of ${ }^{3} \mathrm{He}$ MRI. More widespread ventilation defects or inhomogeneities indicate impaired regional ventilation [63]. The exact threshold between physiological variations and pathological findings has yet to be determined.

Transient ventilation defects in the anterior and posterior lung fields were also observed in subjects with a history of asthma and seasonal allergies, but without noticeable pulmonary symptoms. In some instances, the small peripheral defects seemed to migrate between examinations on different days. These defects were attributed to mucous plugging or bronchospasm [48, 65]. The clinical experience with different lung diseases imaged by ${ }^{3} \mathrm{He}$ gas density techniques is reviewed below.

Smokers. Smoking leads to chronic inflammation and obstruction of small airways. Corresponding ventilation defects were depicted by ${ }^{3} \mathrm{He}$ MRI. In a preliminary prospective study [50], the imaging findings of five clinically healthy smokers (mean $\mathrm{FEV}_{1} \%$ predicted, $104 \%$ ) and five nonsmokers (mean $\mathrm{FEV} 1 \%$ pred, $101 \%$ ) were compared using a score corresponding to the number of defects $\cdot \operatorname{scan}^{-1}$. Otherwise, healthy smokers 
with normal PFTs had a median score of 1.1 (range $0.8-6.0$ ), whereas nonsmokers only had a score of 0.4 (range $0.1-0.8$ ). Although the number of subjects was too small to calculate significance, there is a strong indication that smokers can be differentiated from healthy nonsmokers. With FEV1 being normal, ${ }^{3} \mathrm{He}$ MRI demonstrates potentially reversible airway diseases at an early stage. Since there was no correlation with the number of pack-yrs, ${ }^{3} \mathrm{He}$ MRI may even be capable of detecting the subgroup of smokers at risk of developing severe airway disease.

Chronic obstructive pulmonary diseaselemphysema. Chronic inflammation of central and peripheral airways leads to airway narrowing, loss of elastic recoil, expiratory collapse, and destruction of alveolar walls with enlargement of peripheral airspaces. DE LANGE et al. [48] investigated 13 healthy subjects and three subjects with a smoking history and COPD. Extensive ventilatory defects were found in a patient with known severe emphysema and corresponded to defects seen with ${ }^{133} \mathrm{Xe}$ ventilation scintigraphy several months earlier. COPD and emphysema were associated with multiple ventilation defects $[46,63]$. The defects were round or wedge-shaped, patchy or wide-spread, small or large with whole segments or lobes involved. Ventilation defects can be characterized by reduced signal intensity or the complete lack of signal (fig. 6). It has been speculated that certain patterns of ventilation defects can be associated with either more central or peripheral location of bronchial or bronchiolar obstruction, but there has been no evidence to support this hypothesis. It is also unclear how these different patterns are associated with the severity of bronchial obstruction (FEV1, resistance) or hyperinflation (RV, TLC). Consequently, it is an

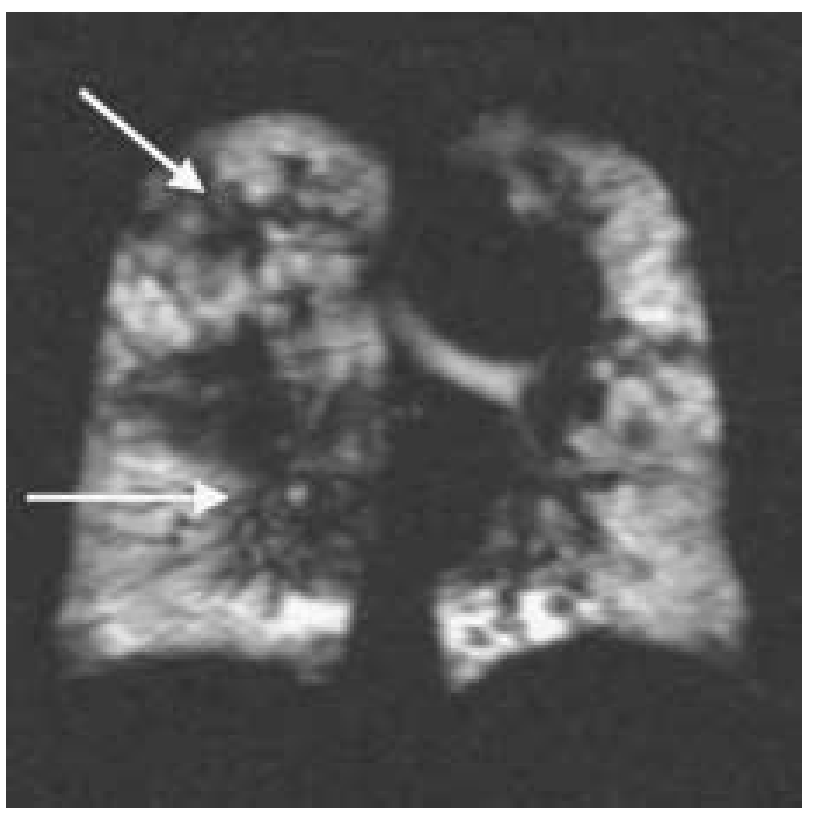

Fig. 6. - Helium-3 $\left({ }^{3} \mathrm{He}\right)$ magnetic resonance image after inhalation of hyperpolarized ${ }^{3} \mathrm{He}$ gas in a 63 -yr-old female with chronic obstructive pulmonary disease showing several small round and wedge-shaped ventilation defects (arrows). open question how size, shape and number of the signal defects can be merged into a common score as a general indicator of functional compromise.

Cystic fibrosis and bronchiectasis. In bronchiectasis, there is marked dilation of the bronchi and bronchial wall thickening leading to delayed and impaired ventilation of distal airspaces and hypoxic vasoconstriction. DonNelly et al. [66] investigated four patients with cystic fibrosis using $\mathrm{H}-1$ and ${ }^{3} \mathrm{He}$ MRI. In all subjects, severe ventilation abnormalities were seen in many lung zones using ${ }^{3} \mathrm{He}$ MRI despite minimal or minor morphologic abnormalities at $\mathrm{H}-1$ MRI. Ventilation defects ranged from wedge-shaped peripheral defects to signal voids in entire lung zones. Ventilation was most severely impaired in the upper posterior lung zones, and normal in the lower lung zones. The ${ }^{3} \mathrm{He}$ MRI score was much more sensitive than the Brasfield chest radiography score, and showed good correlation with PFT results. Comparable observations with multiple wedge-shaped ventilation defects have been reported in a patient with bronchiectasis due to chronic infection [63]. The findings were more severe than expected from CT, which showed the morphological equivalent with bronchial dilatation and bronchial wall thickening.

Asthma. Asthma attacks are caused by the acute narrowing of airways due to exogenous factors. Patients with asthma exhibited markedly more ventilation defects compared to healthy volunteers [64]. These defects were pleural-based, frequently wedge-shaped and variable in size from tiny to segmental. Seven out of 10 asthmatic subjects had $\geqslant 1$ nonposterior defect (fig. 7). Mildly symptomatic asthmatics had larger and more numerous defects than asymptomatic ones. At follow-up, the mildly symptomatic asthmatics had multiple ventilation defects in different locations. Use of a bronchodilator partially or completely resolved the defects. These observations indicate that ${ }^{3} \mathrm{He} \mathrm{MRI}$ is capable of detecting disease in asymptomatic or only mildly symptomatic patients. It is surprising that these ventilation defects are amenable to inhaled therapies (bronchodilators). Thus, ${ }^{3} \mathrm{He}$ MRI may be used as a basis for the continuation of treatment in asthma patients even with normal PFTs.

Lung transplantation, bronchiolitis obliterans. The early diagnosis of chronic allograft rejection/bronchiolitis obliterans after lung transplantation, a major cause of long-term morbidity and mortality, is of paramount importance for the introduction of adequate treatment. In a preliminary study, all lung transplant patients $(n=6)$ had ventilatory defects using ${ }^{3} \mathrm{He}$ MRI [67]. The extent of ventilation defects correlated with the severity of bronchiolitis obliterans using an established clinical grading system. ${ }^{3} \mathrm{He}$ MRI was more sensitive than scintigraphy and CT in the detection of these ventilation defects (fig. 8). Further investigations in single lung transplant recipients showed preferential ventilation of the nonrejected transplant in comparison with the native lung, by comparatively higher signal intensity [68]. Directly after transplantation, some minor defects 

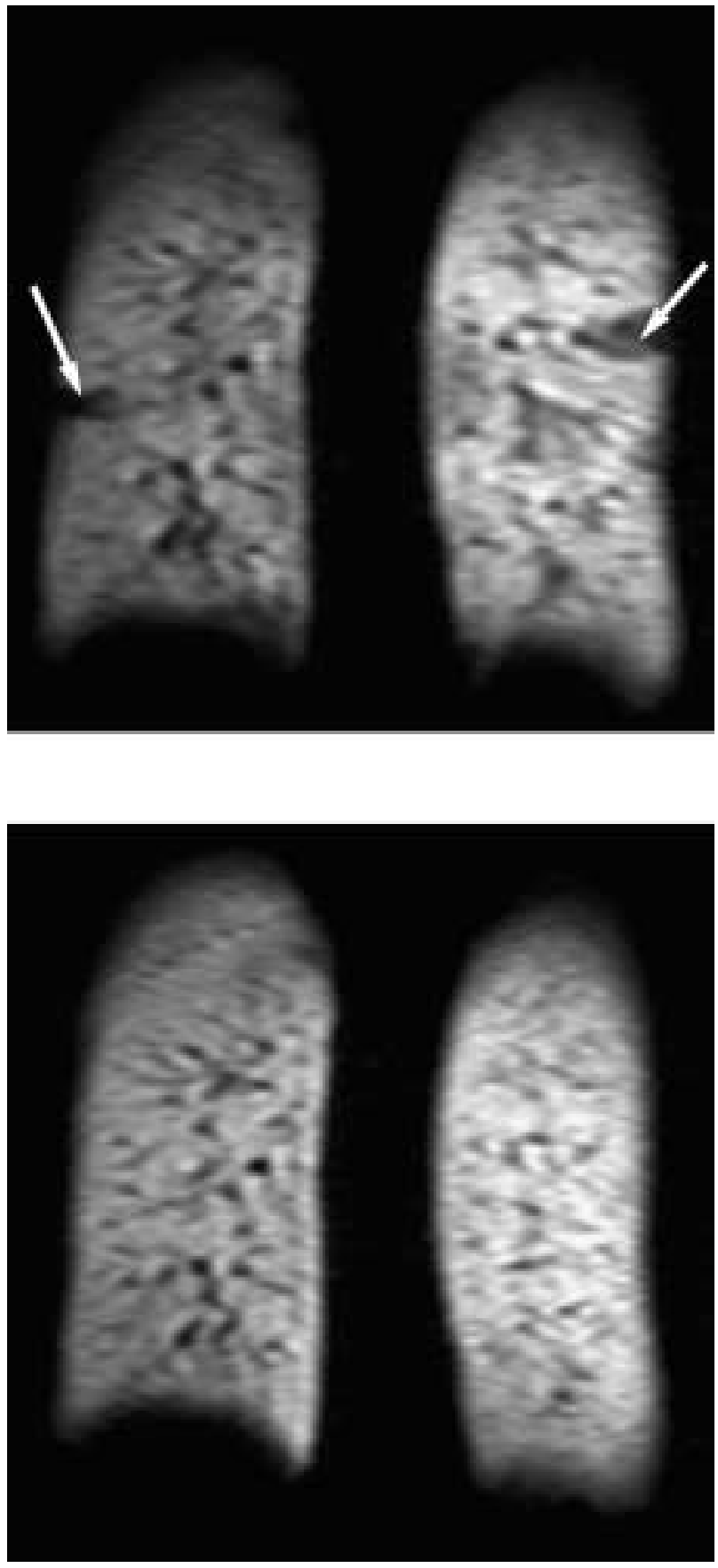

Fig. 7. - Helium-3 $\left({ }^{3} \mathrm{He}\right)$ magnetic resonance images after inhalation of hyperpolarized ${ }^{3} \mathrm{He}$ gas in a female asthmatic showing a) wedge-shaped peripheral defects (arrows), b) which resolve after use of a bronchodilator. (Courtesy of Tally Altes, University of Virginia, Charlottesville, USA).

were recognized, which resolved in the subsequent 6-9 months, indicating postoperative dystelectases. Ventilation defects that developed later after transplantation indicated bronchiolitis or pneumonia. Large ventilation defects in the transplanted lung were associated with a concomitant increase of signal intensity in the native lung, qualitatively indicating that ventilation of the native lung increased when the function of the transplant is impaired.

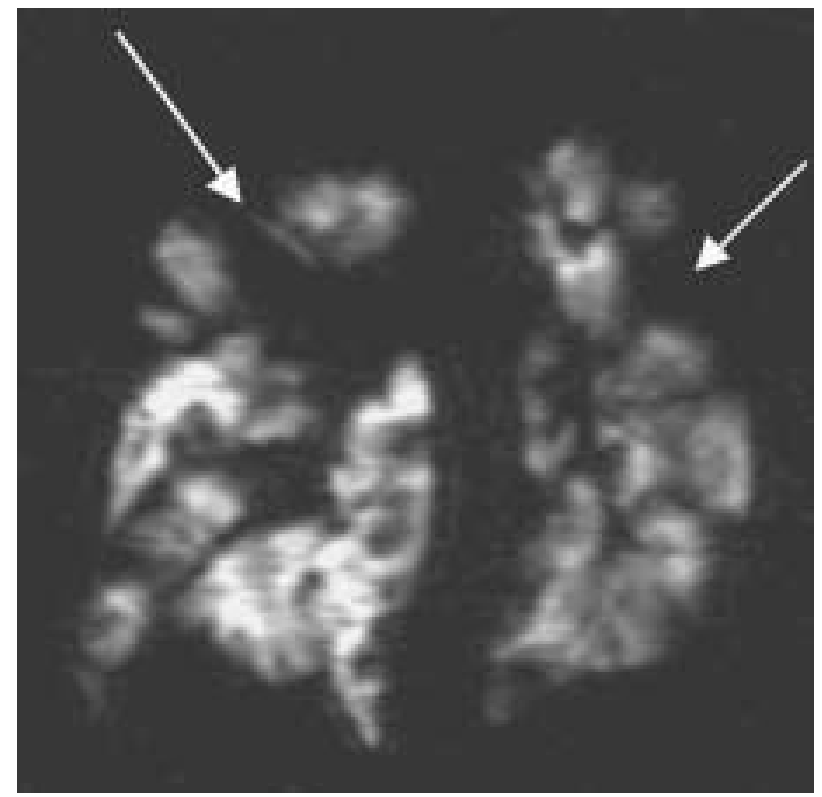

Fig. 8. - Helium-3 $\left({ }^{3} \mathrm{He}\right)$ magnetic resonance image after inhalation of hyperpolarized ${ }^{3} \mathrm{He}$ gas in a 62 -yr-old female with bronchiolitis after double lung transplantation showing multiple ovoid and wedge-shaped ventilation defects (arrows).

Pulmonary embolism. Thus far, there have been no reports of the application of ${ }^{3} \mathrm{He}$ MRI for the diagnosis of acute pulmonary embolism in humans. Animal experiments have shown that ${ }^{3} \mathrm{He}$ MRI can be used as a complementary modality for joint assessment of ventilation and perfusion [34]. Patients with chronic thromboembolic pulmonary hypertension showed typical $V^{\prime} / Q^{\prime}$ mismatches in combined ${ }^{3} \mathrm{He}$ MRI and MRA.

Fibrosis. Patients with fibrosis have not been investigated systematically by ${ }^{3} \mathrm{He}$ MRI. There are only anecdotal reports [63], and results from patients after single lung transplantation for fibrosis [69]. Fibrosis has been more closely associated with a heterogeneous distribution of signal intensity, rather than with distinct defects [63]. The most likely cause is the lack of ventilation defects caused from bronchial obstruction. The heterogeneity indicates regional differences in ventilatory states, time constants, compliance and oxygen concentration. Functional and clinical significance of these findings are still to be investigated.

Masses. Masses displace airspaces and cause signal defects. The defects will be approximately the size of the lesion plus some small surrounding areas due to compression from the mass. These effects have been observed in tumours, such as bronchogenic carcinoma, mediastinal lymphadenopathy, pleural effusion and emphysema [63]. Surprisingly, a pleural effusion causes a massive ventilation defect by compression in supine position [63].

Interobserver correlation testing shows little variation in assessment of abnormalities by different reviewers: in $53 \%$ of cases, equal ratings were given 
by two reviewers on a scoring system based on size and number of defects, as well as signal change [48]. Thus, interpretation of spin density images is reproducible, which is important for clinical acceptance of ${ }^{3} \mathrm{He}$ MRI.

The high sensitivity in the detection of ventilation defects is associated with low specificity. Complementary imaging techniques will be necessary to increase specificity by obtaining further functional information. These techniques include: 1) diffusion-weighted imaging; 2) dynamic imaging during continuous respiration; and 3) measurement of intrapulmonary oxygen concentration.

\section{Helium-3 diffusion imaging in animals}

A unique difference between conventional protonMRI and hyperpolarized gas imaging, is the degree of diffusive motion. All liquids and gases have an inherent property of random microscopic molecular movement, called Brownian motion. This property is represented by the diffusion coefficient. Typically, gases have diffusion coefficients that are $10^{4}-10^{5}$ times greater than those of liquids. The diffusion coefficient can be used to calculate a diffusion length; the average distance a molecule travels per unit time. The diffusion coefficient is not directly related to convection and diffusion by which air reaches alveoli during breathing. In that case, diffusive gas movement follows a concentration gradient. When hyperpolarized gas molecules are in the lung airspaces, the diffusive Brownian motion is measured by MRI during breathholding without a concentration gradient. Since the airspaces are of an order smaller than the diffusion length of ${ }^{3} \mathrm{He}$, the diffusive motion is restricted and a smaller apparent diffusion coefficient (ADC) is measured. The diffusive motion can be used as a contrast parameter in MR images by using specialized pulse sequences. A magnetic field gradient is used to coherently disrupt the signal. However, the same strength field gradient applied in the opposite direction will reconstitute the signal. If the molecules have moved due to diffusion in between the application of these field gradients, the signal from that region will be attenuated. For instance, using a heavily diffusionweighted sequence will result in total destruction of signal in the large airways, but signal will still remain in the distal airspaces. Using a series of diffusion-weighted images, an ADC map can be calculated. From the diffusion map, it has been shown that the ${ }^{3} \mathrm{He}$ diffusive motion can change as much as a factor of 10 in a healthy guinea-pig lung [70]. The ADC measured in the trachea was $2.4 \mathrm{~cm}^{2} \cdot \mathrm{s}^{-1}$, whereas the average ADC in the alveolar spaces was $0.16 \mathrm{~cm}^{2} \cdot \mathrm{s}^{-1}$. This technique has been applied to a rat model of emphysema, showing significant differences between healthy and diseased lungs [49]. Differences in alveolar size detected using MR diffusion techniques were in the order of $20 \mu \mathrm{m}$, as verified by histology.

\section{Helium-3 diffusion imaging in humans}

In a pilot study of four volunteers, BROOKEMAN et al. [71] investigated the potential of MR imaging with ${ }^{3} \mathrm{He}$ to assess regional and age-related distribution patterns of gas diffusion. The diffusion maps of ${ }^{3} \mathrm{He}$ in the healthy human lungs had uniformly distributed ADC values with a mean value of $0.2-0.3 \mathrm{~cm}^{2} \cdot \mathrm{s}^{-1}$. However, older subjects, had higher ADC values with larger standard deviations (SDs). These trends are consistent with an increase in alveolar size, as a result of gradual loss of interstitial lung tissue. An anteroposterior gradient in ADC values was measured in healthy volunteers, corresponding to smaller airspaces in the posterior lung regions (supine position during the examination) [72]. This effect will be minimal at full inspiration and more obvious on expiratory scans. It has also been demonstrated that ADC measurements are highly reproducible with an SD $<0.03 \mathrm{~cm}^{2} \cdot \mathrm{s}^{-1}[72]$. In further studies, the ADC values of normal healthy volunteers where compared with patients with COPD [73] and patients with severe emphysema [74]. In the trachea, the ADC was measured between $0.9-1.0 \mathrm{~cm}^{2} \cdot \mathrm{s}^{-1}$, and reduced values were found in the alveolar spaces of healthy lungs $\left(0.2-0.4 \mathrm{~cm}^{2} \cdot \mathrm{s}^{-1}\right)$. However, in COPD and emphysema patients, alveolar ADC values ranged from $0.4-0.9 \mathrm{~cm}^{2} \cdot \mathrm{s}^{-1}$ indicating an increase of airspace size. Broadening of the histogram represented the heterogeneity of emphysematous destruction. The typical apical predominance of centrilobular emphysema could also be demonstrated [73].

ADC mapping in emphysema patients, however, is limited by the concomitant ventilation defects. HANISCH et al. [75] determined ADC values of ${ }^{3} \mathrm{He}$ in the trachea $\left(0.67 \mathrm{~cm}^{2} \cdot \mathrm{s}^{-1}\right)$, in normal parenchyma $\left(0.13 \mathrm{~cm}^{2} \cdot \mathrm{s}^{-1}\right)$ and in lung fibrosis with honeycombing $\left(0.35 \mathrm{~cm}^{2} \cdot \mathrm{s}^{-1}\right)$. In normal lungs, diffusive gas movement was isotropic, whereas in fibrosis and emphysema, diffusion was anisotropic. This may indicate a nonspherical change in geometry of the alveoli and a preferential direction for diffusive gas movement [76].

These measurements reveal a new approach for differentiating normal from diseased lung. Higher ADC values seen in severe emphysema are consistent with increased alveolar size as a result of alveolar wall destruction. Diffusion imaging of the human lung may aid in the assessment of emphysema and other diseases that alter alveolar size or may be associated with reduced elastic recoil of the alveoli. Further investigations of preferential directions for diffusive gas movement (anisotropy) might lead to the evaluation of local compliance. Diffusion imaging might be an important complement of gas density imaging to increase the specificity of ${ }^{3} \mathrm{He} \mathrm{MRI}$, potentially leading to several important clinical applications. First, it will be possible to perform cross-sectional population studies to determine the normal ageing pattern of the lung, which will determine a normal range of values. With the standard range, the influence of exogenous factors, such as smoking and industrial exposure to substances, can be studied. Also, the normal range can be used as a metric for early identification of emphysema in patients at risk and test industrial compensation. ADC measurements can also be used as a research tool for early treatment of emphysema. As new drugs become available, both the efficacy and the long-term effects could be studied using ADC values. Finally, ADC 
measurement could contribute in the determination of patients suitable for lung volume reduction surgery as well as for follow-up of patients with $\alpha-1$ antitrypsin deficiency receiving substitution therapy.

\section{Helium-3 dynamic imaging in animals}

Another unique aspect of gas imaging is the ability to directly image dynamic ventilatory function. With the appropriate imaging sequences, cine imaging can show continuous visualization of the respiratory cycle, including inspiration, distribution of ${ }^{3} \mathrm{He}$ within the alveolar space, and expiration. Distribution analysis of normal and abnormal ventilated regions and corresponding time constants becomes feasible.

In animal studies, timing of breathing must be regulated by mechanical ventilation. By synchronizing the excitation pulse with influx of gas, it is possible to image the gas as it enters into the lungs $[77,78]$. There are several parameters that can be varied to obtain dramatically different types of images: the flip angle, the length of the acquisition window, and the placement of the acquisition window. These parameters have been explored in a study by CHEN et al. [79], which showed airway branching down to the 5th order. More sophisticated development of pulse sequences have resulted in "movies" of ventilation with temporal resolutions of $50 \mathrm{~ms}$ [80].

\section{Helium-3 dynamic imaging in humans}

In human studies, real-time techniques have been developed to visualize the distribution of ventilation. High temporal resolution was achieved $(40-130 \mathrm{~ms})$, but with reduced spatial resolution [81, 82]. Images have been obtained in the coronal or transverse plane, but it is still unclear which orientation is best suited for distribution analysis. In healthy volunteers, the distribution of ${ }^{3} \mathrm{He}$ was observed in the trachea (time-topeak $260 \mathrm{~ms}$ ), the mainstem bronchi, the peripheral airways and in alveolar space (time-to-peak $910 \mathrm{~ms}$ ) [82].

GIERADA et al. [83] recently investigated the distribution of ${ }^{3} \mathrm{He}$ in healthy volunteers and emphysema patients. Patients with smoking-related centrilobular emphysema had severe ventilation defects predominately in the upper lobes. Distribution during the first inhalation of ${ }^{3} \mathrm{He}$ was characterized by sequential filling of nonsegmental lung regions interspersed with unfilled regions. The signal distribution became more homogeneous during rebreathing of the ${ }^{3} \mathrm{He}$ gas from a bag. This observation was attributed to collateral ventilation and represents different intrapulmonary time constants. The authors demonstrated that severely diseased regions (as determined from CT) correlated with delayed or absent ventilation at ${ }^{3} \mathrm{He}$ MRI. Washout was significantly prolonged in emphysema patients with signal persisting in some regions, most likely due to gas retention and low oxygen concentration (increased T1-time).

There are several potential clinical applications for dynamic ventilation imaging. Typically, impaired distribution with delayed ventilation in lung regions distal to diseased airways will precede the development of significant ventilation defects. Thus, dynamic ${ }^{3} \mathrm{He}$ MRI may help in early detection of obstructive airway disease, when the disease is still reversible. Another application for dynamic imaging is to determine impaired ventilation patterns in different types of emphysema. Emphysema caused by smoking tends to result in diffuse changes, whereas congenital or nonsmoking related emphysema have more focal changes. Since the latter group is more likely to benefit from lung volume reduction surgery, regional data about impaired ventilation distribution may be helpful in surgical planning.

\section{Helium-3 measurements of intrapulmonary oxygen concentration in animals and humans}

The partial pressure of oxygen $\left(\mathrm{PO}_{2}\right)$ in ventilated airspaces of the lung varies due to local imbalances between $V^{\prime} / Q^{\prime}$. Routinely, alveolar $V^{\prime} / Q^{\prime}$ is measured indirectly in end-expiratory gas at the mouth, and compared to the $\mathrm{PO}_{2}$ in arterial and venous blood. From these global measurements, physiological models allow calculation of compartmental $\mathrm{PO}_{2}$ values in the lungs. However, these values do not give the true $\mathrm{PO}_{2}$ present at a specific time and location in the alveolar space. Regional imbalances of $V^{\prime} / Q^{\prime}$ ratios, however, may be an important indicator for potentially reversible lung diseases which are compensated by physiological regulation mechanisms, such as hypoxic vasoconstriction, and may support planning of thoracic surgery.

The T1-time of ${ }^{3} \mathrm{He}$ in the lung is $\sim 20 \mathrm{~s}$. Within the airspaces, the irreversible polarization loss of ${ }^{3} \mathrm{He}$ and the continual loss of signal is mainly caused by radiofrequency pulses and relaxation due to paramagnetic molecular oxygen $[84,85]$. There is a linear dependency between the concentration of oxygen and the relaxation time of hyperpolarized ${ }^{3} \mathrm{He}$ as has been demonstrated in vitro [84]. This property has been used to compute the intrapulmonary oxygen concentration in live pigs [86]. By measuring the relaxation times of the hyperpolarized ${ }^{3} \mathrm{He}$ gas within the animal lungs during two different imaging series, EBERLE and coworkers [86, 87] were able to make use of this phenomenon to compute the intrapulmonary oxygen concentration in vivo from ${ }^{3} \mathrm{He}$ MRI images. The values sampled from large alveolar regions correlated significantly with global end-expiratory values from conventional respiratory gas analysis $(\mathrm{r}=0.88)$. DENINGER et al. [88] utilized this relaxation effect to determine the local oxygen partial pressure and to quantify time-dependent changes of $\mathrm{PO}_{2}$ in human volunteers. The temporal evolution of $\mathrm{PO}_{2}$ during apnoea was found to be linear, both in an animal model and a human volunteer. These preliminary results yielded physiologically plausible measurements for initial $\mathrm{PO}_{2}$ and rates of $\mathrm{PO}_{2}$ decrease with time (R). The apparent correlation between $\mathrm{PO}_{2}$ with the decrease rate $\mathrm{R}$, indicates the local matching of ventilation and perfusion and reflects the relative 
contributions of alveolar space and peripheral anatomical deadspace to a volume of interest.

In conclusion, measurements of $\mathrm{PO}_{2}$ give indirect evidence about lung perfusion. This unique information is clinically important in identifying regions of $V^{\prime} / Q^{\prime}$ mismatch in diseased lungs, which cannot be obtained by any laboratory method or clinically applicable technique measuring true $\mathrm{PO}_{2}$ regionally. Patients suffering from lung diseases with $V^{\prime} / Q^{\prime}$ imbalance, like pulmonary embolism or bronchiectasis, may have a method for early detection by noninvasive ${ }^{3} \mathrm{He}$ MRI measurements of $\mathrm{PO}_{2}$.

\section{Xenon-129: gas- and dissolved-phase studies}

$\mathrm{Xe}$ is another inert noble gas that can be imaged using MR techniques (fig. 9). One of the main differences between ${ }^{129} \mathrm{Xe}$ and ${ }^{3} \mathrm{He}$ is the solubility of $\mathrm{Xe}$ in blood and lipid-rich tissue, thus dissolved-phase imaging is possible [55]. Using inhalation techniques, only a small fraction $(\sim 2 \%)$ of $\mathrm{Xe}$ is dissolved into lung parenchyma or blood. Once Xe enters the blood stream it is distributed throughout the body by circulation. Thus, it is possible to perform chemical shift imaging in the lung, kidney, and brain, as has been demonstrated in rats $[52,89]$. The resonance of $\mathrm{Xe}$ is strongly influenced by its environment and thus, a chemical shift occurs. The dissolved-phase resonances of Xe are shifted by $\sim 200$ parts per million from the gas-phase resonance. Spectra measured in humans and rats have shown resonances that correspond to fat, tissue, and red blood cells. The collection of gas- and

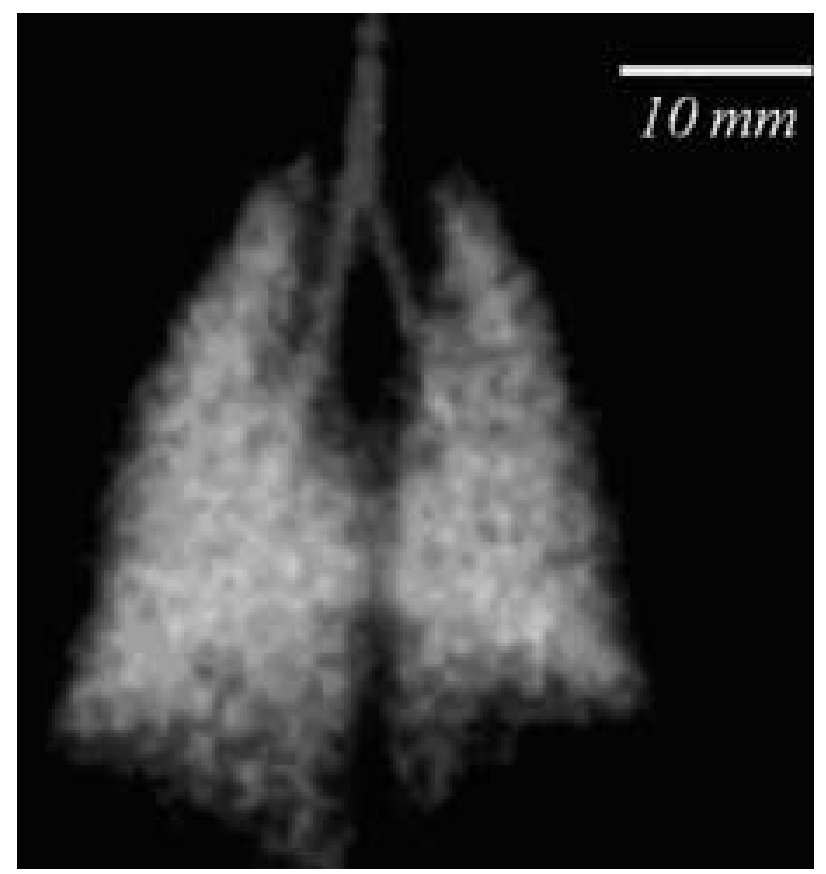

Fig. 9. - Xenon-129 $\left({ }^{129} \mathrm{Xe}\right)$ magnetic resonance image (volume rendered) after inhalation of hyperpolarized ${ }^{129} \mathrm{Xe}$ gas in a live guinea-pig showing rather homogeneous distribution of ventilation. Data acquisition was synchronized with the breathing cycle and was restricted to breath-hold periods of $384 \mathrm{~ms}$ at full inspiration. (Reproduced from [51] with permission). dissolved-phase signal is possible within a single acquisition. In 1997, MUGLER et al. [61] achieved combined imaging and spectroscopic approach in two human volunteers. Comparing ${ }^{129} \mathrm{Xe}$ and $\mathrm{H}-1$ images, they found good correlation between the gas-space signal void in the proton images and the gas-space signal in Xe-images. Combined imaging of the gasphase and dissolved-phase ${ }^{129} \mathrm{Xe}$ MRI may lead towards simultaneous $V^{\prime} / Q^{\prime}$ studies of the lung. Further studies into the dynamics of $\mathrm{Xe}$ in the chest have been studied in the dog [53]. After inhalation, the signal from tissue (or red blood cells) was destroyed. The signal decay in the gas-phase was observed, providing a measure of the absorption of Xe into the tissue. Time constants of $61 \mathrm{~ms}$ were measured for tissue saturation with $\mathrm{Xe}$ and $70 \mathrm{~ms}$ for red blood cell saturation.

The high solubility of Xe into the blood stream makes it possible to use it as a diffusible tracer for measurements of $Q^{\prime}$ of different organs, such as lung and brain. However, there are a number of drawbacks to using $\mathrm{Xe}$ as a $Q^{\prime}$ agent. Xe has anaesthetic properties, which limit its amount and hence signal, available for a study. The deficiency in signal is further compounded by low polarization rates. Early studies were limited to $2 \%$ [60], while more recent studies have reported levels up to $5-7 \%[52,53]$. Using isotopically enriched ${ }^{129} \mathrm{Xe}$ gas $(71-79 \%)$ improves the signal, but is about 20 times more expensive than naturally abundant ${ }^{129} \mathrm{Xe}$.

Fluorine-containing compounds as magnetic resonancecontrast agents for ventilation imaging in animals

The low spin density of the intrapulmonary gases can be compensated for not only by hyperpolarization of the spin system, but also by using either a high number of signal averages $[90,91]$, or by increasing the spin density by filling in a fluid compatible with oxygen or carbon dioxide gas exchange. These two approaches have shown to be feasible when performed with fluorinated substances. Since the MR-visible isotope ${ }^{19} \mathrm{~F}$ has both a high natural abundance as well as high gyromagnetic ratio, a high sensitivity of ${ }^{19} \mathrm{~F}$ MRI can be achieved when compared to H-1 MRI.

Fluorinated gases. In physiologically inert fluorinated gases such as tetrafluoromethane $\left(\mathrm{CF}_{4}\right)$, hexafluoroethane $\left(\mathrm{C}_{2} \mathrm{~F}_{6}\right)$, or sulphur hexafluoride $\left(\mathrm{SF}_{6}\right)$ a high number of signal averages can be used to compensate for the low spin density of the gases, while keeping the scan time in an acceptable range. A relatively strong MR signal is obtained from of the large number of F-atoms per molecule. $\mathrm{SF}_{6}$ gas is almost insoluble in blood [92], has no known toxic effects, and has been used for more than two decades in patients as part of multiple inert gas elimination technique (MIGET). The first application of ${ }^{19} \mathrm{~F}$ MRI of an $\mathrm{O}_{2} /$ $\mathrm{CF}_{4}$ gas mixture in dog lung was presented by RINCK et al. [93] in 1984. A good agreement between the distribution of $\mathrm{CF}_{4}$ gas and $\mathrm{Xe}$ was demonstrated in a beagle dog with pneumonia after a scan time of $25 \mathrm{~min}$. Recently, KuETHE et al. [90] demonstrated that $\mathrm{C}_{2} \mathrm{~F}_{6}$ gas 
can be used to obtain 3D high-resolution ventilation scans $(0.7 \mathrm{~mm}$ pixel size) in rat lungs within $4 \mathrm{~h}$. Scan times could be reduced to $30 \mathrm{~min}$ by using $\mathrm{SF}_{6}$ gas instead of $\mathrm{C}_{2} \mathrm{~F}_{6}$ [94]. Estimation of the $V^{\prime} / Q^{\prime}$ ratio was achieved in an animal model with partial bronchial obstruction by comparing the signal while breathing a gas mixture with high $\mathrm{SF}_{6}$ and low $\mathrm{O}_{2}$ concentration and one with low $\mathrm{SF}_{6}$ and high $\mathrm{O}_{2}$ concentration [94]. For potential human applications, scan times of fluorinated gases have to be significantly shorter. $3 \mathrm{D}$ images of $\mathrm{SF}_{6}$, homogeneously distributed in porcine lungs, were obtained during a single breath-hold of 49 s (fig. 10) by using a special MR sequence and by increasing the voxel size to $4.7 \times 6.3 \times 15 \mathrm{~mm}^{3}$ [95]. Dynamic imaging of $\mathrm{SF}_{6}$ with a temporal resolution of $9.1 \mathrm{~s}$ also visualized wash-in and wash-out with a time constant dependent on the tidal volume [96]. Further developments are required for human applications of fluorinated gas MRI to avoid potential peripheral nerve stimulation, and to keep the specific absorption rate within acceptable levels [95].

Perfluorocarbon compounds and liquid ventilation. In the last two decades, perfluorocarbon compounds (PFCs) have received increased interest because of their high solubility for gases like $\mathrm{O}_{2}$ and $\mathrm{CO}_{2}$ [97]. A new therapeutic strategy for the treatment of acute respiratory distress syndrome (ARDS) is based on the intrapulmonary application of PFC (partial liquid $V^{\prime}$ ) [98]. Although ${ }^{19} \mathrm{~F}$ MRI under conditions of liquid $V^{\prime}$ has been shown as early as in the mid 1980s [97], this technique has rarely been used. Recently, imaging with high spatial $\left(2.9 \times 2.2 \times 15 \mathrm{~mm}^{3}\right)$ and temporal resolution (34 s) was achieved in partial liquid $V^{\prime}$ in pigs. Moreover, they were able to measure the regional intrapulmonary $\mathrm{PO}_{2}$ using the well known effects of

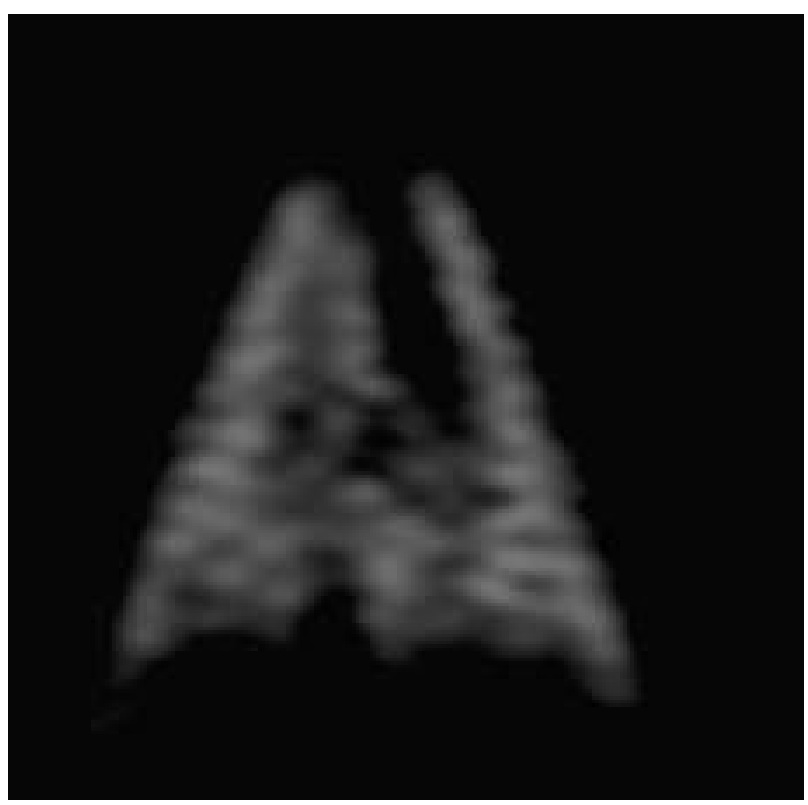

Fig. 10. - Fluorine-19 magnetic resonance image after inhalation of $80 \%$ sulphur-hexafluoride gas in a pig showing rather homogeneous distribution of ventilation and the two mainstem bronchi. (Reproduced from [95] with permission). paramagnetic oxygen on the MR-characteristics of PFC [99]. Magnetic resonance imaging in clinical algorithms of
patient-work-up

The developments of MR for $V^{\prime}$ imaging have now reached preliminary clinical studies. The charm of these new techniques is that they can be used to obtain information about ventilation, perfusion, anatomical and functional data in a nonionizing radiation environment. This allows for repeated studies to assess treatment response. Further development of MR ventilation imaging will involve demonstration of superiority over nuclear medicine procedures (while some competition with CT also exists). Higher sensitivity and specificity for recognized diseases will need to be shown, as well as demonstration of improved clinical significance for well-recognized indications. Finally, the new ability to incorporate more refined functional information should show improved definition of disease states, which should change the selection of more refined drug and surgical therapies (dependent on the type and state of the disease process). Thus, early detection and treatment of obstructive lung disease could result in reversibility of the disease process, which could lead to improved prognosis of the illness. Furthermore, the treatment regime could be based on more individual parameters leading to improved quality of life, changed treatment modalities and could influence the handling of riskful situations, such as anaesthesia. This can be achieved by demonstrating impaired distribution of $V^{\prime}$, changes of diffusive gas movement in the peripheral airways or by different regional oxygen concentration. The forthcoming years will show which MRI-techniques will finally prevail or whether several methods will be established in conjunction with different clinical indications.

\section{Summary}

Technological advances have already radically changed morphological lung imaging in the last $20 \mathrm{yrs}$. It can be expected that the field will change even more with the introduction of MR-based functional imaging strategies of ventilation and perfusion (table 1). With the unique possibility of mapping functional information, an exciting new field of interdisciplinary research has emerged. There will be a focus on real-time analysis of the distribution of ventilation as well as the assessment of regional ventilation/perfusion ratios. From the existing studies that have been conducted in small series of patients, it seems warranted to evaluate the high sensitivity of the magnetic resonance techniques in a broader clinical environment with respect to early detection of obstructive airway disease. Although pulmonary function tests are nonsensitive, they are generally accepted in decision-making with respect to treatment or change of treatment. More sensitive techniques might change the indications for treatment or certain treatment options. Of the technologies 
discussed, oxygen enhancement might be the first which becomes generally available because of ease of implementation and the complementary nature to magnetic resonance angiography and perfusion imaging. The major drawback will be the limited amount of functional information. For measures in lung functionality, hyperpolarized gas magnetic resonance imaging is superior, and there is optimism that it will prove clinically important and have an impact on the management of patients with obstructive lung disease.

\section{References}

1. van Beek E, van Buul MT, Büller H, van Royen E, ten Cate $\mathrm{J}$. The value of lung scintigraphy in the diagnosis of pulmonary embolism. Eur J Nucl Med 1993; 20: $173-181$.

2. Elgazaar A, Silberstein E, Hughes J. Perfusion and ventilation scans in patients with extensive obstructive airway disease: utility of single-breath (wash-in) xenon-133. J Nucl Med 1995; 36: 64-67.

3. Chiti A, Schreiner F, Crippa F, Pauwels E, Bombardieri E. Nuclear medicine procedures in lung cancer. Eur J Nucl Med 1999; 26: $533-555$.

4. Wernly JA, DeMeester TR, Kirchner PT, Myerowitz PD, Oxford DE, Golomb HM. Clinical value of quantitative ventilation-perfusion lung scans in the surgical management of bronchogenic carcinoma. J Thorac Cardiovasc Surg 1980; 80: 535 - 543.

5. White P, Hayward M, Cooper T. Ventilation agents what agents are currently used? Nucl Med Commun 1991; 12: 349-352.

6. Senden T, Moock K, Gerald J, et al. The physical and chemical nature of technegas. J Nucl Med 1997; 38: $1327-1333$.

7. Suga K, Nishigauchi K, Kume N, et al. Ventilation abnormalities in obstructive airways disorder: detection with pulmonary dynamic densitometry by means of spiral CT versus dynamic Xe-133 SPECT. Radiology 1997; 202: 855-862.

8. Nagao M, Murase K, Ichiki T, Sakai S, Yasuhara Y, Ikezoe J. Quantitative analysis of technegas SPECT: evaluation of regional severity of emphysema. $\mathrm{J} \mathrm{Nucl}$ Med 2000; 41: 590-595.

9. Murata K, Itoh H, Senda M, Todo G, Yonekura Y, Torizuka K. Ventilation imaging with positron emission tomography and nitrogen 13. Radiology 1986; 158: $303-307$.

10. Schuster D. The evaluation of lung function with PET. Semin Nucl Med 1998; 28: 341 - 351.

11. Rhodes C, Hughes J. Pulmonary studies using positron emission tomography. Eur Respir J 1995; 8: $1001-1017$.

12. Kramer SS, Hoffman EA. Physiologic imaging of the lung with volumetric high-resolution CT. J Thorac Imag 1995; 10: 280-290.

13. Kauczor H-U, Hast J, Heussel C, Schlegel J, Mildenberger $\mathrm{P}$, Thelen $\mathrm{M}$. Focal airtrapping at expiratory high-resolution CT: comparison with pulmonary function tests. Eur Radiol 2000; 10: $1539-1546$.

14. Markstaller K, Kauczor H-U, Eberle B, et al. Multirotations-CT während kontinuierlicher Beatmung: Vergleich unterschiedlicher Dichtebereiche bei gesunden 
Lungen und im Lavage-ARDS Modell. Fortschr Röntgenstr 1999; 170: 575-580.

15. Gevenois PA, DeVuyst P, Sy M, et al. Pulmonary emphysema: quantitative CT during expiration. Radiology 1996; 199: 825-829.

16. Cassart M, Pettiaux N, Gevenois P, Paiva M, Estenne M. Effect of chronic hyperinflation on diaphragm length and surface area. Am J Respir Crit Care Med 1997; 156: $504-508$.

17. Kauczor H-U, Klamm R, Heussel C, Fischer B, Mildenberger $\mathrm{P}$, Thelen $\mathrm{M}$. Assessment of lung volumes using spiral CT in inspiration and expiration: comparison with pulmonary function tests. AJR 1998; 171: $1091-1095$.

18. Estenne $\mathrm{M}$, Cassart $\mathrm{M}$, Poncelet $\mathrm{P}$, Gevenois $\mathrm{P}$. Volume of graft and native lung after single lung transplantation for emphysema. Am J Respir Crit Care Med 1999; 159: 641-645.

19. Simon B, Marcucci C, Fung M, Lele S. Parameter estimation and confidence intervals for Xe-CT ventilation studies: a Monte Carlo approach. J Appl Physiol 1998; 84: 709-716.

20. Thiele J, Klöppel R. Computertomographische Messung der Lungenventilation durch Inhalation von Isovist 300. Röntgenpraxis 1995; 48: 259-260.

21. Kauczor H-U. Contrast-enhanced MRA of the pulmonary vasculature. Invest Radiol 1998; 33: $606-$ 617.

22. Hatabu H, Tadamura E, Levin DL, et al. Quantitative assessment of pulmonary perfusion with dynamic contrast-enhanced MRI. Magn Reson Med 1999; 42: $1033-8$.

23. Kreitner K-F, Ley S, Kauczor H-U, et al. Assessment of chronic thromboembolic pulmonary hypertension by three-dimensional contrast-enhanced MR angiography: comparison with selective intraarterial DSA. Fortschr Röntgenstr 2000; 172: $122-128$.

24. Gierada D, Hakimian S, Slone R, Yusen R. MR analysis of lung volume and thoracic dimensions in patients with emphysema before and after lung volume reduction surgery. AJR 1998; 170: 707-714.

25. Suga $\mathrm{K}$, Tsukuda $\mathrm{T}$, Awaya $\mathrm{H}$, et al. Impaired respiratory mechanics in pulmonary emphysema: Evaluation with dynamic breathing MRI. J Magn Reson Imag 1999; 19: 510-520.

26. Cluzel P, Similowski T, Chartrand-Lefebvre C, Zelter M, Derenne JP, Grenier P. Diaphragm and chest wall: assessment of the inspiratory pump with MR imaging - preliminary observations. Radiology 2000; 215: 574583.

27. Steiner P, McKinnon G, Romanowski B, Goehde S, Hany T, Debatin J. Contrast-enhanced, ultrafast 3D pulmonary MR angiography in a single breath-hold: initial assessment of imaging performance. J Magn Reson Imag 1997; 7: 177-182.

28. Meaney J, Weg J, Chenevert T, Stafford-Johnson D, Hamilton B, Prince M. Diagnosis of pulmonary embolism with magnetic resonance angiography. $N$ Engl J Med 1997; 336: 1422-1427.

29. Brouwers-Kuyper E, Berghou A, Bongaerts A, van Beek E, Oudkerk M. Diagnosis of pulmonary embolism: a comparative analysis of contrast enhanced MR angiography with pulmonary angiography. Eur Radiol 2000; 10: Suppl. 1, 208-209.

30. Nolte-Ernsting C, Adam G, Bücker A, Berges S, Bjornerud A, Günther RW. Experimental evaluation of superparamagnetic iron oxide nanoparticles for pulmonary MR angiography. Fortschr Röntgenstr 1998; 168: 509-514.

31. Berthezene Y, Croisille P, Bertocchi M, Houzard C, Bendib K, Revel D. Lung perfusion demonstrated by contrast-enhanced dynamic magnetic resonance imaging: application to unilateral lung transplantation. Invest Radiol 1997; 32: 351-356.

32. Hatabu H, Gaa J, Kim D, Li W, Prasad P, Edelman R. Pulmonary perfusion: quantitative assessment with dynamic contrast-enhanced MRI using ultra-short TE and inversion recovery turbo FLASH. Magn Reson Med 1996; 36: $503-508$

33. Wielopolski P, Oudkerk M, van Ooijen P. Magnetic resonance imaging and angiography of the pulmonary vascular system. In: Oudkerk M, van Beek E, ten Cate J, eds. Pulmonary embolism.Berlin, Blackwell Science, 1999: pp. 250-329.

34. Viallon M, Berthezène $\mathrm{Y}$, Décorps $\mathrm{M}$, et al. Laserpolarized $3 \mathrm{He}$ as a probe for dynamic regional measurements of lung perfusion and ventilation using magnetic resonance imaging. Magn Reson Med 2000; 44: $1-4$.

35. Berthezene $\mathrm{Y}$, Vexler V, Clement O, Mühler A, Moseley M, Brasch R. Contrast-enhanced MR imaging of the lung: assessments of ventilation and perfusion. Radiology 1992; 183: 667-672.

36. Misselwitz B, Muhler A, Heinzelmann I, Bock J, Weinmann H. Magnetic resonance imaging of pulmonary ventilation Initial experiences with a gadoliniumDTPA-based aerosol. Invest Radiol 1997; 32: $797-$ 801.

37. Haage P, Adam G, Pfeffer J, et al. Demonstration of pulmonary ventilation in MR imaging of the lung: initial results with a gadolinium-DTPA aerosol. Fortschr Röntgenstr 2000; 172: 323-328.

38. Edelman R, Hatabu H, Tadamura E, Lei W, Prasad P. Noninvasive assessment of regional ventilation in the human lung using oxygen-enhanced magnetic resonance imaging. Nature Medicine 1996; 2: 1236-1239.

39. Löffler R, Mueller C, Peller M, et al. Optimization and evaluation of the signal intensity change in multisection oxygen-enhanced MR lung imaging. Magn Reson Med 2000; 43: 860-866.

40. Carr H, Purcell E. Effects of diffusion on free precession in nuclear magnetic resonance experiments. Phys Rev 1954; 94: 630-638.

41. Mai V, Chen Q, Bankier A, Edelman R. Multiple inversion recovery MR subtraction imaging of human ventilation from inhalation of room air and pure oxygen. Magn Reson Med 2000; 43: 913 -916.

42. Chen Q, Levin D, Kim D, et al. Pulmonary disorders: ventilation-perfusion MR imaging with animal models. Radiology 1999; 213: 871-879.

43. Bouchiat MA, Carver TR, Varnurn CM. Nuclear polarization in $3 \mathrm{He}$ gas induced by optical pumping and dipolar exchange. Phys Rev Lett 1960; 5: $373-$ 375 .

44. Colegrove FD, Schearer LD, Walters K. Polarization of 3He gas by optical pumping. Phys Rev 1963; 132: $2561-2572$.

45. Black RD, Middleton HL, Cates GD, et al. In vivo He-3 MR images of Guinea pig lungs. Radiology 1996; 199: $867-870$.

46. Kauczor H-U, Surkau R, Roberts T. MRI using hyperpolarized noble gases. Eur Radiol 1998; 8: 820827.

47. Middleton H, Black RD, Saam B, et al. MR imaging 
with hyperpolarized 3He Gas. Magn Res Med 1995; 33: $271-275$

48. de Lange E, Mugler J, Brookeman J, et al. Lung air spaces: MR imaging evaluation with hyperpolarized He gas. Radiology 1999; 210: 851-857.

49. Chen JX, Hedlund LW, Moeller HE, Chawla MS, Maronpot RR, Johnson GA. Detection of emphysema in rat lungs using magnetic resonance measurements of 3He diffusion. Proc Natl Acad Sci 2000; 97: 11478 11481 .

50. Guenther D, Eberle B, Hast J, et al. 3He MRI in healthy volunteers: preliminary correlation with smoking history and lung volumes. NMR Biomed 2000; 13: $182-189$.

51. Moller HE, Chen XJ, Chawla MS, et al. Sensitivity and resolution in 3D NMR microscopy of the lung with hyperpolarized noble gases. Magn Reson Med 1999; 41: $800-808$.

52. Swanson S, Rosen M, Coulter K, Welsh R, Chupp T. Distribution and dynamics of laser-polarized 129Xe magnetization in vivo. Magn Reson Med 1999; 42: $1137-1145$.

53. Ruppert K, Brookeman J, Hagspiel K, Driehuys B, Mugler J. NMR of hyperpolarized Xe-129 in the canine chest: spectral dynamics during a breath-hold. NMR Biomed 2000; 13: 220-228.

54. Darrasse L, Guillot G, Nacher PJ, Tastevin G. Lowfield $3 \mathrm{He}$ nuclear magnetic resonance in human lungs. C R Acad Sci Paris 1997; 324: 691-700.

55. Albert MS, Cates GD, Driehuys B, et al. Biological magnetic resonance imaging using laser-polarized 129 Xe. Nature 1994; 370: 199-201.

56. Wagshul M, Button $\mathrm{T}$, $\mathrm{Li} \mathrm{H}$, et al. In vivo $\mathrm{MR}$ imaging and spectroscopy using hyperpolarised 129Xe. Magn Reson Imag 1996; 36: 183-191.

57. Hedlund LW, Moeller HE, Chen XI, Chawla MS, Cofer CP, Johnson GA. Mixing oxygen with hyperpolarized $3 \mathrm{He}$ for small-animal lung studies. NMR Biomed 2000; 13: 202-206.

58. Ebert M, Grobmann T, Heil W, et al. Nuclear magnetic resonance imaging on humans using hyperpolarized 3He. Lancet 1996; 347: 1297-1299.

59. Kauczor H-U, Hofmann D, Kreitner KF, et al. Normal and abnormal pulmonary ventilation: visualization at hyperpolarized He-3 MR imaging. Radiology 1996; 201: 564-568.

60. MacFall J, Charles H, Black R, et al. Human lung air spaces: potential for MR imaging with hyperpolarized He-3. Radiology 1996; 200: 553-558

61. Mugler JP, Driehuys B, Brookeman JR, et al. MR imaging and spectroscopy using hyperpolarized 129Xe gas: preliminary human results. Magn Reson Med 1997; 37: 809-815.

62. Kauczor H-U, Markstaller K, Puderbach M, Lill J, Eberle B, Thelen M. Volumetry of ventilated airspaces using 3He MRI: comparison with pulmonary function tests. Invest Radiol 2001; 36: 110-114.

63. Kauczor H-U, Ebert M, Kreitner KF, et al. Imaging of the lungs using 3He MRI: preliminary clinical experience. J Magn Reson Imag 1997; 7: $538-543$.

64. Altes T, Powers P, Knight-Scott J, et al. Hyperpolarized $3 \mathrm{He}$ MR lung ventilation imaging in asthmatics: preliminary findings. Proc Intl Soc Mag Reson Med 2000; 8: 5 .

65. Hagspiel K, Mugler J, Altes $\mathrm{T}$, et al. Static MR imaging of the airways using hyperpolarized $3 \mathrm{He}$ and
129Xe: The University of Virginia experience. Eur Radiol 1999; 9: B20.

66. Donnelly LF, MacFall JR, McAdams HP, et al. Cystic Fibrosis: Combined hyperpolarized $3 \mathrm{He}-$ enhanced and conventional proton MR imaging in the lung - preliminary observations. Radiology 1999; 212: $885-889$.

67. McAdams H, Palmer S, Donnelly L, Charles H, Tapson V, MacFall J. Hyperpolarized 3He-enhanced MR Imaging of Lung Transplant Recipients: Preliminary Results. AJR 1999; 173: 955-959.

68. Kauczor H-U, Eberle B, Lill J, et al. Funktionelle Strategien zur Untersuchung der Ventilation bei einseitig Lungentransplantierten mittels He-3 MRT. Fortschr Röntgenstr 2000; 172: S16.

69. Kauczor H-U, Schreiber W, Markstaller K, et al. He-3 MRI in healthy smokers, non-smokers, and lung transplant recipients: comparison with pulmonary function tests. Proc Intl Soc Magn Reson Med 2000; 8: 2198.

70. Chen X, Moeller H, Chawla M, et al. Spatially resolved measurements of hyperpolarized gas properties in the lung in vivo. Part I: diffusion coefficient. Magn Reson Med 1999; 42: 721 - 728.

71. Brookeman J, Mugler J III, Knight-Scott J, Munger T, de Lange E, Bogorad P. Studies of $3 \mathrm{He}$ diffusion coefficient in the human lung: age-related distribution patterns. Eur Radiol 1999; 9: B21.

72. Salerno M, Brookeman J, de Lange E, Knight-Scott J, Mugler J III. Demonstration of an alveolar-size gradient in the healthy human lung: a study of the reproducibility of hyperpolarized $3 \mathrm{He}$ diffusion MRI. Proc Intl Soc Mag Reson Med: 2000: 2195.

73. Salerno M, Brookeman J, de Lange E, Knight-Scott J, Mugler J III. Detection of regional microstructural changes of the lung in emphysema using hyperpolarized 3He diffusion MRI. Proc Intl Soc Mag Reson Med: 2000: 9.

74. Saam B, Yablonskiy DA, Gierada D, Cooper J, Lefrak S, Conradi M. Measuring diffusivity of $3 \mathrm{He}$ in human lung: Preliminary study of patients with emphysema. Eur Radiol 1999; 9: B22.

75. Hanisch G, Schreiber W, Diergarten T, et al. Investigation of intrapulmonary diffusion by $3 \mathrm{He}$ MRI. Eur Radiol 2000; 10: S 345.

76. Hanisch G, Schreiber W, Kauczor H-U, et al. Determination of diffusion anisotropy in the lung by Helium-3 MRI. Eur Radiol 2000; 10: G3.

77. Johnson $\mathrm{G}$, Cates $\mathrm{G}$, Chen $\mathrm{X}$, et al. Dynamics of magnetization in hyperpolarized gas MRI of the lung. Magn Reson Med 1997; 38: 66-71.

78. Moller HE, Chen XJ, Chawla MS, Driehuys B, Hedlund LW, Johnson GA. Signal dynamics in magnetic resonance imaging of the lung with hyperpolarized noble gases. J Magnetic Reson 1998; 135: $133-143$.

79. Chen X, Chawla M, Hedlund L, Moeller H, MacFall J, Johnson G. MR microscopy of lung airways with hyperpolarized 3He. Magn Reson Med 1998; 39: $79-$ 84.

80. Viallon M, Cofer G, Suddarth S, et al. Functional MR microscopy of the lung with hyperpolarized $3 \mathrm{He}$. Magn Reson Med 1999; 41: 787-792.

81. Saam B, Yablonskiy DA, Gierada DS, Conradi MS. Rapid imaging of hyperpolarized gas using EPI. Magn Reson Med 1999; 42: 507-514.

82. Schreiber W, Weiler N, Kauczor H-U, et al. Ultrafast 
MR-Imaging of ventilation using hyperpolarized Helium-3. Fortschr Röntgenstr 2000; 172: 129-133.

83. Gierada D, Saam B, Yablonskiy D, Cooper J, Lefrak S, Conradi M. Dynamic echo planar MR imaging of lung ventilation with hyperpolarized $\mathrm{He}-3$ in normal subjects and patients with severe emphysema. NMR Biomed 2000; 13: 176-181.

84. Saam B, Happer W, Middleton H. Nuclear relaxation of $3 \mathrm{He}$ in the presence of $\mathrm{O}_{2}$. Phys Rev 1995; 52: 862-865.

85. Markstaller K, Eberle B, Deninger A, et al. Flip angle considerations in quantification of intrapulmonary oxygen concentration by Helium-MRI. NMR Biomed 2000; 13: 190-193.

86. Eberle B, Weiler N, Markstaller K, et al. Analysis of regional intrapulmonary $\mathrm{O}_{2}$-concentrations by $\mathrm{MR}$ imaging of inhaled hyperpolarized helium-3. J Appl Physiol 1999; 87: 2043-2052.

87. Deninger A, Eberle B, Ebert M, et al. Quantitation of regional intrapulmonary oxygen partial pressure evaluation during apnoea by 3He-MRI. JMR 1999; 141: $207-216$.

88. Deninger A, Eberle B, Ebert M, et al. 3He-MRI-based measurements of intrapulmonary $\mathrm{PO}_{2}$ and its time course during apnea in healthy volunteers: first results, reproducibility and technical limitations. $N M R$ Biomed 2000; 13: 194-201.

89. Swanson S, Rosen M, Agranoff B, Coulter K, Welsh R, Chupp T. Brain MRI with laser-polarized Xe-129. Magn Reson Med 1997; 38: 695-698.

90. Kuethe DO, Caprihan A, Fukushima E, Waggoner RA. Imaging lungs using inert fluorinated gases. Magn Reson Med 1998; 39: 85-88.
91. Behr VC. Magnetic resonance imaging and biomedical applications using fluorinated gases [Master of Science]. Albuquerque, New Mexico: University of New Mexico, 1999.

92. Wagner PD, Saltzman HA, West JB. Measurement of continuous distributions of ventilation-perfusion ratios: theory. J Appl Physiol 1974; 36: 588 -599.

93. Rinck PA, Petersen SB, Lauterbur PS. NMR imaging of fluorine-containing substances. 19-Fluorine ventilation and perfusion studies. Fortschr Röntgenstr 1984; 140: $239-243$.

94. Kuethe DO, Caprihan A, Gach HM, Lowe IL, Fukushima E. Imaging of obstructed ventilation with NMR using inert fluorinated gases. $J$ Appl Physiol 2000; 88: 2279-2286.

95. Schreiber W, Markstaller K, Weiler N, et al. Breathhold 19F-Magnetic Resonance Imaging of lung ventilation using SF6 Gas. Fortschr Röntgenstr 2000; 172: $500-503$.

96. Schreiber W, Eberle B, Laukemper-Ostendorf S, et al. Dynamic 19F-MRI of Sulfur Hexafluoride (SF6) Gas in the Lung. Magn Reson Med 2001; 45: 605-613.

97. Thomas SR, Clark LC, Ackerman JL, et al. MR imaging of the lung using liquid perfluorocarbons. J Comput Assist Tomogr 1986; 10: 1 -9.

98. Fuhrmann BP, Paczan PR. Perfluorocarbon-associated gas exchange. Crit Care Med 1991; 19: 712 - 722.

99. Thomas SR, Gradon L, Pratsinis SE, et al. Perfluorocarbon compound aerosols for delivery to the lung as potential $19 \mathrm{~F}$ magnetic resonance reporters of regional pulmonary $\mathrm{PO}_{2}$. Invest Radiol 1997; 32: $29-38$. 